ESSAY REVIEW

\title{
Crackpot Claims Raise Important Issues
}

\section{Plague of Corruption: Restoring Faith in the Promise of Science} by Judy Mikovits and Kent Heckenlively, Foreword by Robert F. Kennedy, Jr. Skyhorse/Children's Health Defense, 2020. 272 pp. \$26.99 (hardcover), \$17.99 (Kindle). ISBN 978-1-5107-5224-5; 9781-5107-5225-2 (ebook).

Plague: One Scientist's Intrepid Search for the Truth about Human Retroviruses and Chronic Fatigue Syndrome (ME/ CFS), Autism, and Other Diseases by Kent Heckenlively and Judy Mikovits. Skyhorse, 2014. 464 pp. \$26.95 (hardcover), \$1.99 (Kindle). ISBN: 978-1-6263-6565-0.

\author{
Reviewed by Henry H. Bauer \\ Virginia Polytechnic Institute \& State University \\ hhbauer@vt.edu; www.henryhbauer.homestead.com \\ https://10.31275/20201861 \\ Creative Commons License CC-BY-NC
}

These two books promptly became best sellers on Amazon after one of the authors, Judy Mikovits, had claimed in a video ${ }^{1}$ that the CoVID-19 pandemic had been planned by a cabal of billionaires (Bill Gates and others) to create a market for vaccines; ${ }^{2}$ that Anthony Fauci was responsible for millions of deaths in the early years of HIV/AIDS; that some vaccines might indeed trigger autism; and that contaminant viruses make the blood supply dangerous. The video went viral on the Internet and social media before being removed from the major platforms. $^{3}$

These books include the same claims, and more, but they are substantively disappointing in failing to offer convincing evidence for the assertions; they are little more than vehicles for Mikovits to re-argue 
the validity of her researches, in such comprehensive and technical detail that few readers will find them interesting. It is never defined, what exactly the "plague" is; presumably, that Mikovits's scientific claims are not sufficiently appreciated.

The most controversial claim may be that Chronic Fatigue Syndrome or Myal gic Encephalomyelitis (CFS/ME, sometimes CFS/ME/ $F M$ to include fibromyalgia) is caused by an infectious retrovirus (RNA virus), specifically $X M R V$; that some vaccines are dangerous through contamination by animal retroviruses, since animal-cell cultures are used in making vaccines-XMRV, a mouse retrovirus, stemming from the use of mouse tissues; that autism, too, has a viral cause and therefore may follow vaccination with contaminated vaccine; and that the nation's blood supply may have become contaminated. The 2014 book claims further that evidence linking autism with MMR (mumps, measles, rubella) vaccination had been suppressed by the Centers for Disease Control and Prevention (CDC); and that two decades earlier the CDC had suppressed the evidence for a viral cause of CFS/ME.

Many critiques of these claims have appeared on the Internet and elsewhere; for a comprehensive debunking of the claims as made specifically in the Plandemic video, see Enserink and Cohen (2020). The claim of finding XMRV in CFS/ME sufferers could not be replicated and eventually the original paper was withdrawn by Science, although Mikovits continues to argue for something closely related to XMRV as the cause of CFS.

\section{CONTENTS OF THE BOOKS}

The books read like first-hand accounts by Mikovits. The 2014 book has long paraphrases from Osler's Web (Johnson, 1996), a comprehensive discussion of CFS by a woman who has herself long suffered from it; the book

documents the sneering opposition of both the Centers for Disease Control and the National Institutes of Health to recognizing CFS as a genuine disease, the hands-off attitude toward it of several leading medical journals, and the obloquy many physicians heaped on it. (Beatty, 1996) 
Outbreaks of CFS in the 1980s led to Mikovits becoming Research Director at the startup Whittemore Peterson Institute for NeuroImmune Disease (WPI), established at the University of Nevada (Reno) by the parents of a daughter long suffering from CFS. Earlier, Mikovits had worked for some 20 years on HIV/AIDS at the National Cancer Institute, then briefly at a couple of other places.

After a disagreement at WPI, Mikovits was fired, and she gives a detailed account of being arrested and spending five days in jail after

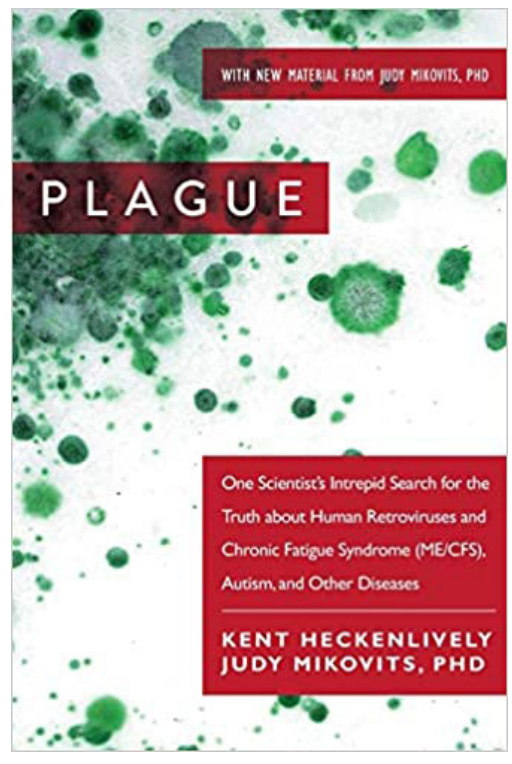
allegedly absconding with her research notebooks. The 2014 book has excruciatingly detailed descriptions of how Mikovits did everything right in her work and in her dispute with WPI; and argues that any blame for mistakes re XMRV should be placed not on Mikovits but on one of her co-authors, an argument repeated at length in the 2020 volume.

Unfortunately, the accounts in these books are far from trustworthy. For instance, Mikovits's assistant at WPI had signed an affidavit that he had taken the notebooks to Mikovits at her request, ${ }^{4}$ something Mikovits continues to deny. The 2014 book even disclaims reliability: "Neither the authors nor the publisher claims [sic] that the conversations are accurately recorded. . . . Many of the primary documents supporting the information found in this book are available at www. plaguethebook.com"; however, I found no supporting documents there, and my query to the publisher about that has not been answered.

Mikovits is even unreliable about HIV, asserting that it had been isolated "from an actual human being," and that Montagnier had isolated it (Heckenlively \& Mikovits, 2014, Chapter 19), when in fact no one has done that; 5 and she calls the Western Blot "the gold standard of molecular virology," even though it was dropped from use (in the UK) for its unreliability as an HIV test. 


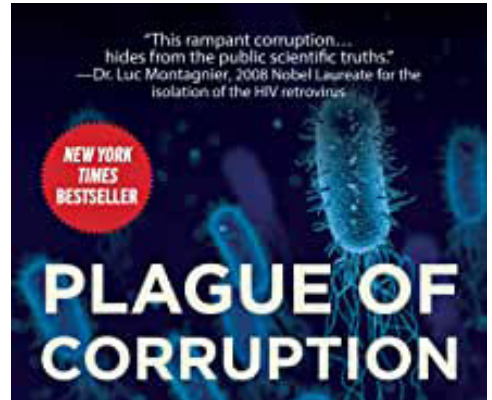

RESTORING FAITH INTHE

PROMISE OF SCIENCE

Dr. Judy Mikovits

$\&$ Kent Heckenlively, JD

Foreword by

Robert F. Kennedy, Jr.

Children's

Health Defense

Another less-than-accurate claim is Mikovits' assertion that as the principal investigator on the pertinent grants she had the right, indeed the duty, to keep possession of the notebooks. However, federal regulations concerning grants require that the institution where the principal investigator held a grant would have needed to agree, $^{6}$ in this case the Whittemore Peterson Institute. More about this below, in the section about the circumstances of doing research in the $21^{\text {st }}$ century.

The 2020 book begins with a lengthy foreword by Robert $F$. Kennedy, Jr., which unfortunately assumes Mikovits's claims to be true. Nevertheless, Kennedy is sound in citing many illustrations of "the 'Semmelweis reflex' ... the knee-jerk revulsion with which the press, the medical and scientific community, and allied financial interests greet new scientific evidence that contradicts an established scientific paradigm" (Mikovits \& Heckenlively, 2020, p. XIII): Herbert Needleman, hounded for drawing attention to the (later accepted as real) dangers from lead in the environment, in particular leaded gasoline; Rachel Carson (DDT killing wildlife); Alice Stewart (child cancers caused by X-raying pregnant women); Bernice Eddy (polio outbreak and cancers caused by defective vaccines); John Anthony Morris (inefficacy of flu vaccines, dangers of swine-flu vaccine); Gary Goldman (danger of chickenpox and shingles caused by vaccine); Peter Gøtzsche, cofounder of the Cochrane Collaboration, ousted for pointing to adverse events from HPV vaccine.

The remainder of the 2020 book, as the earlier 2014 one, argues at length that Mikovits was and is right and everyone else wrong. As one review put it, "Plague of Corruption is, essentially, an act of selfhagiography... . [comparing] Mikovits ... to, among others, Galileo, Martin Luther King Jr., and Thomas Jefferson" (Dickson, 2020).

Although the books will be interesting reading only for those who 
want the details of Mikovits's self-justifications, issues are raised that ought to concern everyone: about HIV/AIDS and viruses and vaccines; that contemporary medicine seems helpless over CFS/ME, autism, and several other chronic ailments; and the circumstances facing researchers in the $21^{\text {st }}$ century.

\section{CFS/ME AND OTHER ILL-DEFINED BUT VERY REAL CHRONIC AILMENTS}

CFS/ME is highly debilitating, and present-day medicine does not understand it: It is

a complicated disorder characterized by extreme fatigue that can't be explained by any underlying medical condition. The fatigue may worsen with physical or mental activity, but doesn't improve with rest.... The cause of chronic fatigue syndrome is unknown, although there are many theories-ranging from viral infections to psychological stress. Some experts believe chronic fatigue syndrome might be triggered by a combination of factors. . . . There's no single test to confirm a diagnosis of chronic fatigue syndrome. You may need a variety of medical tests to rule out other health problems that have similar symptoms. Treatment for chronic fatigue syndrome focuses on symptom relief.?

And those symptoms are anything but specific or idiosyncratic; they may but need not include, as well as fatigue: loss of memory or concentration; sore throat; enlarged lymph nodes; unexplained muscle or joint pain; headaches; unrefreshing sleep; extreme and continuing exhaustion after physical or mental exercise.

Autism, or autism spectrum disorder, has a similarly indefinite set of symptoms that do not allow for definitive, objective, diagnosis. So, too, with Attention-Deficit Disorder (ADHD), ${ }^{8}$ irritable-bowel syndrome, chronic Lyme disease, and more (Bauer, 2014).

The lack of objective markers and definitive descriptions ensures that individuals who suffer such conditions are unlikely to get useful help from any medical practitioner or specialist. Not infrequently the sufferers are treated as though their ailment were psychological or psychosomatic. Quack offers of help and remedies flourish. Groups of sufferers and their relatives form organizations for mutual support and 
to campaign for research. Something similar happens with ailments so rare and obscure that most physicians have no knowledge of them. The daughter of a friend of this reviewer, a highly successful lawyer suddenly struck by seizures, lack of energy, and inability to work, spent several years seeking help before through personal research discovering that she has Hashimoto's Encephalopathy (Nelson et al., 2013); again, my step-grand-daughter was diagnosed eventually by her parents, not by doctors, as having PANDAS—Pediatric Autoimmune Neuropsychiatric Disorders Associated with Streptococcal infections.

Could the several ill-defined but real chronic illnesses have a common cause? The multitude of possible symptoms, neither necessary nor sufficient, and the alleged associations with a number of possible triggering stimuli, indicates a systemic condition that can be set off by a variety of happenings; perhaps it is the cell danger response (CDR), which can affect several or even all physiological functions (Naviaux, 2020). This suggestion also offers a plausible explanation for why several of these illnesses-autism, for one-seem (but perhaps only seem [Wright, 2017]) to have become more common in recent decades.

Since CFS/ME frequently occurs in geographic clusters and discrete outbreaks, one plausible trigger is some infectious agent; a variety of studies have suggested several without agreement following on any of them, as with Mikovits's claim that it is a mouse retrovirus, $\mathrm{XMRV}$ or closely related to it.

\section{MIKOVITS, XMRV, AND THE LEGACY OF HIV/AIDS}

Mikovits graduated as a major in chemistry and began work as a technician in Robert Gallo's laboratory at the National Cancer Institute just as AIDS was starting to be of concern. Much or even all of what has gone wrong for Mikovits can rather plausibly be blamed on her having learned virology under Gallo's influence just as he and others were going badly wrong over HIV and AIDS. That Gallo is not a competent researcher was widely known long ago, albeit only within the profession (Mullis, 1998, p. 176); nor was his reputation one of honesty or integrity: He had actually been found guilty of scientific misconduct over HIV (Cohen, 1993; Crewdson, 2002).

Before HIV, viruses had been characterized after isolation of pure viral particles (virions) by some combination of ultra-filtration and ultra- 
centrifugation, as verified by electron microscopy. But the claimed and accepted discovery of HIV was based purely on indirect indications: first, the detection of reverse transcriptase, which is pervasively present in mammalian cells but was thought at the time to depend on the presence of a retrovirus; second, antibody tests developed on nonpurified "isolates" (Bauer, 2007, p. 92 ff.). Subsequently, purportedly quantitative measurements of HIV, the so-called viral load, have been based on PCR (polymerase chain reaction), which is universally used to detect DNA or RNA. However, it does not find actual virions of HIV, the virus itself, but only pieces of DNA or RNA presumed to be HIVspecific.

Quite appropriately, therefore, the HIV-test kits warn that they are not valid for diagnosis of infection by HIV: a warning that has been ignored in practice, globally, for more than three decades.

Those faulty bases for claiming detection and identification of retroviruses have become standard. No wonder, then, that claims like Mikovits's could not be replicated by others, or even by herself in later work. Even as some publications (Arias \& Fan, 2014; Panelli et al., 2017) continue to point out that PCR is unreliable for detecting or identifying $X M R V$, for example, the practice continues; major journals publish peer-reviewed articles in which PCR was applied on unpurified "isolates." PCR could become reliable only if pure virions of the virus in question had first been isolated and then their genomes identified to find RNA or corresponding DNA sequences specific to that virus. Instead, PCR continues to be used on unpurified mixtures to the extent of even claiming "whole-genome-sequencing."

Controversies over viruses will continue inevitably until the methodology for isolating and identifying becomes reliable. In the meantime, there will continue to be claims and counterclaims based on flawed techniques: that a mouse virus, XMRV, is the cause of prostate cancer (Urisman et al., 2006) and CFS/ME (Lombardi et al., 2009); no, it isn't (Simmons et al., 2011).

That viruses remain poorly understood (Raoult, 2014) is illustrated by the discovery less than two decades ago of viruses much larger than viruses were supposed to be (La Scola et al., 2003); and that these "giant" viruses can be themselves infected by smaller viruses (La Scola et al., 2008). 
The terrible legacy of "HIV" is not only that unreliable, misleading methods now seem to be an integral part of virology; it has also entrenched the concept of antiretroviral drugs, which are invariably and inevitably highly toxic since they target not only reactions that facilitate viral replication but are also reactions that mammalian cells use in their ordinary activities.

The evidence is quite conclusive that HIV had nothing to do with AIDS, 9 and it is clear how the mistake came about and why it persists (Bauer, 2007). Mullis (1998, Chapter 18) has recorded that no one, including the discoverers of HIV, could cite a published primary source proving that AIDS is caused by HIV. The most primary source reported detecting (of course by faulty and unreliable methods) HIV in " 18 of 21 patients with pre-AIDS ... [and] 26 of 72 adult and juvenile patients with AIDS" (Gallo et al., 1984). Similarly, Mikovits had claimed XMRV as a cause because it was present in $2 / 3$ of pertinent cases. That does not make it a necessary cause; and to show that it is a partial, occasionally contributory cause, the mechanism by which it produces the claimed effect would need to be identified. With HIV, after a quarter of a century, it remains a mystery how it is supposed to accomplish destruction of the immune system; in the case of XMRV, no mechanism was even proposed.

The assumption that association equals causation is another sad legacy of HIV/AIDS, though it is common enough, sadly, in just about all contemporary medicine.

\section{SCIENTIFIC RESEARCH IN THE $21^{\text {st }}$ CENTURY}

Mikovits spent several days in jail over a dispute about the ownership of her research notebooks. That points to circumstances in essentially all research nowadays: Researchers do not own the products of their own work.

Since the increasingly great resources needed for research are provided by a government agency or a private foundation or an academic institution, the funding source can and usually does insist on ownership rights in the products of the research. Quite a little industry has grown up about the apportioning of ownership rights in "intellectual property," even though the only intellectual input comes from the researchers. 
The extent to which the researchers benefit from what the research has produced depends on prior agreements. Kary Mullis won a Nobel Prize for his invention of the polymerase chain reaction (PCR), but it was the commercial company for which he had worked at the time that profited from patenting the discovery, which gave Mullis himself an almost insulting token only (Mullis, 1998, p. 11). Academic institutions may not behave any more appropriately than do commercial enterprises. Anthony Linnane, FRS, FAA (Nagley, 2018), had established a Center for Molecular Biology at Monash University in Australia through raising large sums of money from outside sources. When he retired from his academic position and wished to move the Center to a different location, Monash University insisted that everything in the Center was owned by the University. Linnane was successful in disputing the University's claim in a civil court, but I am unaware of any comparable such success by an individual researcher in Australia or elsewhere. When I moved from the University of Kentucky, I wanted to take with me a useful little gadget bought under a grant that I had been awarded as Principal Investigator, and the head of my Department agreed, but the bureaucrat in charge of the university's equipment inventory did not. The Attorney General of Virginia tried in court to have Michael Mann, former faculty member at the University of Virginia, produce his research notes about climate change for scrutiny. Even worse have been several cases where academic researchers obtained results displeasing to their commercial sponsors who tried, sometimes successfully, to prevent publication of the research results.

The conventional wisdom continues to think of scientists as independent intellectual entrepreneurs, but that view is badly outdated. It was only up to about WWII that science was something like a cottage industry of voluntarily cooperating, independent, largely disinterested ivory-tower intellectual entrepreneurs, where science was free to do its own thing, namely the unfettered seeking of truth about the natural world. Nowadays it is a bureaucratic corporate-industry-government behemoth, with science pervasively co-opted by outside interests that pay for and thereby control the choices of research projects and the decisions of what to publish and what not to make public (Bauer, 2017). Researchers nowadays get the opportunity to do their work only at the expense of losing ownership in the resulting intellectual property; what 
part of the benefits from that property they later enjoy depends on negotiations with those who provide the resources and whose power is dominant. This seems quite analogous to the circumstances of crofters in the old days in the Scottish Highlands, or of sharecroppers in the old days in the American South. Perhaps the scientific community should try to establish appropriate guidelines for what rights researchers should have as to publication of their work and participation in worldly material profits resulting from their efforts. Presumably the laborer is worthy of his hire, after all.

\section{NOTES}

1 Plandemic. https://newyorkcityguns.com/watch-the-banned-video-plandemic/

2 Search "Event 2021" on Google for this conspiracy theory.

3 Wong, Q., \& Solsman, J. E. (2020, May 8). Facebook, YouTube and Twitter struggle with viral Plandemic conspiracy video. c/net. https:// www.cnet.com/news/facebook-youtube-twitter-viral-plandemicconspiracy-video/

4 'Plandemic': Was Judy Mikovits arrested without a warrant and jailed without charges? https://www.snopes.com/fact-check/plandemicmikovits-arrest/

5 The case against HIV. http://thecaseagainsthiv.net, section 3.1.3

${ }^{6} \mathrm{NIH}$ : Change of recipient organization (Transfers). https://www. niams.nih.gov/grants-funding/administering-grant/changegrantee-institution-transfers

7 Mayo Clinic: Chronic Fatigue Syndrome. https://www.mayoclinic.org/ diseases-conditions/chronic-fatigue-syndrome/symptoms-causes/ syc-20360490

8 ADHD Rating Scale-IV (ADHD-RS). https://www.psychcongress.com/ saundras-corner/scales-screeners/adhd/adhd-rating-scale-iv-adhd-rs

9 The case against HIV. http://thecaseagainsthiv.net

\section{REFERENCES}

Arias, M., \& Fan, H. (2014). The saga of XMRV: A virus that infects human cells but is not a human virus. Emerging Microbes and Infections, 3(5), e37. https:// www.ncbi.nlm.nih.gov/pmc/articles/PMC4008767

Bauer, H. H. (2007). The origin, persistence and failings of HIV/AIDS theory. McFarland. 
Bauer, H. H. (2014). Medical mysteries and conundrums-When doctors may not help. Journal of Scientific Exploration, 28, 130-137.

Bauer, H. H. (2017). Science is not what you think: How it has changed, why we can't trust it, how it can be fixed. McFarland.

Beatty, W. (1996, February 1). Review of Osler's Web. Booklist.

https://www.booklistonline.com/Osler-s-Web-Inside-the-Labyrinth-of-theChronic-Fatigue-Syndrome-Epidemic-Hillary-Johnson/pid=992653

Cohen, J. (1993). HHS: Gallo guilty of misconduct. Science, 259, 168-170.

Crewdson, J. (2002). Science fictions: A scientific mystery, a massive cover-up, and the dark legacy of Robert Gallo. Little, Brown.

Dickson, E. J. (2020, May 12). Judy Mikovits, disgraced doctor at the center of 'Plandemic,' has a bestselling book on Amazon: 'Plague of Corruption' is gaining traction on the heels of a proliferation of COVID-19 conspiracy theories. Rolling Stone. https://www.rollingstone.com/culture/culture-news/plandemicjudy-mikovits-plague-of-corruption-998224/

Enserink, M., \& Cohen, J. (2020, May 8). Fact-checking Judy Mikovits, the controversial virologist attacking Anthony Fauci in a viral conspiracy video. Science. https://www.sciencemag.org/news/2020/05/fact-checking-judy-mikovitscontroversial-virologist-attacking-anthony-fauci-viral\#

Gallo, R. C., Salahuddin, S. Z., Popovic, M., Shearer, G. M., Kaplan, M., et al. (1984). Frequent detection and isolation of cytopathic retroviruses (HTLV-III) from patients with AIDS and at risk for AIDS. Science, 224, 500-503.

Johnson, H. (1996). Osler's web: Inside the labyrinth of the Chronic Fatigue Syndrome epidemic. Crown.

La Scola, B., Audic, S., Robert, C., Jungang L., de Lamballerie, X., et al. (2003). A giant virus in amoebae. Science, 299, 2033.

La Scola, B., Desnues, C., Pagnier, I., Robert, C., Barassi, L., et al. (2008). The Virophage as a unique parasite of the Giant Mimivirus. Nature, 455, 100-104. Lombardi, V. C., Ruscetti, F. W., Das Gupta, J., Pfost, M. A., Hagen, K. S., et al. (2009). Detection of an infectious retrovirus, XMRV, in blood cells of patients with Chronic Fatigue Syndrome. Science, 326, 585-589.

Mullis, K. (1998). Dancing naked in the mind field. Pantheon.

Nagley, P. (2018). Anthony (Tony) W. Linnane: A man of mitochondria and much more. International Union of Biochemistry and Molecular Biology, 70, 256-259.

Naviaux, R. K. (2020). Perspective: Cell danger response biology-The new science that connects environmental health with mitochondria and the rising tide of chronic illness. Mitochondrion, 51, 40-45.

Nelson, N., Foley, S., \& Lawler, S., for the Hashimoto's Encephalopathy SREAT Alliance. (2013). Understanding Hashimoto's Encephalopathy: A guide for patients, families, and caregivers. CreateSpace. ISBN 978-1484883099.

Panelli, S., Lorusso, L., Balestrieri, A., Lupo, G., \& Capelli, E. (2017). XMRV and 
public health: The retroviral genome is not a suitable template for diagnostic PCR, and its association with Myalgic Encephalomyelitis/Chronic Fatigue Syndrome appears unreliable. Frontiers in Public Health, 5, \#108. https://doi.org/10.3389/fpubh.2017.00108

Raoult, D. (2014, February 28). The discovery of more and more viruses of recordbreaking size calls for a reclassification of life on Earth. The Scientist. https://www.the-scientist.com/features/viruses-reconsidered-37867

Simmons, G., Glynn, S. A., Komaroff, A. L., Mikovits, J. A., Tobler, L. H., et al., for the Blood XMRV Scientific Research Working Group (SRWG). (2011). Failure to confirm XMRV/MLVs in the blood of patients with Chronic Fatigue Syndrome: A multi-laboratory study. Science, 334, 814-817.

Urisman, A., Molinaro, R. J., Fischer, N., Plummer, S. J., Casey, G., et al. (2006). Identification of a novel gammaretrovirus in prostate tumors of patients homozygous for R462Q RNASEL variant. PLoS Pathogens, 2(3), e25.

Wright, J. (2017, March 3). The real reasons autism rates are up in the U.S.: A hard look at whether the rise comes from more awareness, better diagnosisor something else. Spectrum (Scientific American online). https://www. scientificamerican.com/article/the-real-reasons-autism-rates-are-up-in-the-u-s/ 